\title{
Tensile Behavior of Unidirectional Bamboo/Coir Fiber Hybrid Composites
}

\author{
Le Quan Ngoc Tran ${ }^{1, *}$, Carlos Fuentes ${ }^{2}$, Ignace Verpoest ${ }^{2}$ and Aart Willem Van Vuure ${ }^{2, *}$ \\ 1 Agency for Science, Technology and Research, Singapore Institute of Manufacturing Technology, (A*STAR), \\ 73 Nanyang Drive, Singapore 637662, Singapore \\ 2 Department of Materials Engineering (MTM), KU Leuven, Kasteelpark Arenberg 44, 3001 Leuven, Belgium \\ * Correspondence: tranlqn@simtech.a-star.edu.sg (L.Q.N.T); aartwillem.vanvuure@kuleuven.be (A.W.V.V.); \\ Tel.: +65-6793-8958 (L.Q.N.T.); +32-16-30 1138 (A.W.V.V.)
}

Received: 14 May 2019; Accepted: 6 July 2019; Published: 10 July 2019

check for updates

\begin{abstract}
Natural fibers, such as bamboo, flax, hemp, and coir, are usually different in terms of microstructure and chemical composition. The mechanical properties of natural fibers strongly depend on the organization of cell walls and the cellulose micro-fibril angle in the dominant cell wall layers. Bamboo, flax, and hemp are known for high strength and stiffness, while coir has high elongation to failure. Based on the unique properties of the fibers, fiber hybridization is expected to combine the advantages of different natural fibers for composite applications. In this paper, a study on bamboo/coir fiber hybrid composites was carried out to investigate the hybrid effect of tough coir fibers and brittle bamboo fibers in the composites. The tensile behavior of unidirectional composites of bamboo fibers, coir fibers, and hybrid bamboo/coir fibers with a thermoplastic matrix was studied. The correlation between the tensile properties of the fibers and of the hybrid composites was analyzed to understand the hybrid effects. In addition, the failure mode and fracture morphology of the hybrid composites were examined. The results suggested that, with a low bamboo fiber fraction, a positive hybrid effect with an increase of composite strain to failure was obtained, which can be attributed to the high strain to failure of the coir fibers; the bamboo fibers provided high stiffness and strength to the composites.
\end{abstract}

Keywords: natural fibers; hybridization; Unidirectional (UD) composites

\section{Introduction}

Fiber-reinforced polymer composites are attractive materials for a wide range of applications due to their high strength and stiffness in combination with light weight. Modern composite structures are increasingly subjected to multiple performance criteria, in which the optimum combination of mechanical properties (e.g., strength, stiffness, and toughness), cost, and sustainability are considered. Fiber hybridization has recently received a high interest in research and application for creating hybrid composites having synergetic properties. The fiber-hybrid composites provide more design freedom than non-hybrid composites, and possibly lead to synergetic effects that neither of constituents possess [1-5].

In order to achieve the synergies in fiber-hybrid composites, several aspects play important roles, including selection of suitable fibers, selection of suitable fiber combination and understanding fiber interactions in the hybrid systems. While there is substantial information on fiber-hybridization for synthetic fiber composites [4,6-8], the understanding of hybrid effects in natural fiber composites is still limited.

Natural fibers, such as bamboo, flax, hemp, and coir, extracted from plants, are usually different in terms of microstructure and chemical composition. The mechanical properties of natural fibers 
strongly depend on the organization of cell walls and the cellulose micro-fibril angles in the cell wall layers. Bamboo, flax, and hemp are known for high strength and stiffness, while coir has high strain to failure $[9,10]$. Based on the unique properties of the fibers, fiber hybridization is expected to combine the advantages of the different natural fibers for composite applications.

In this study, tensile behavior of unidirectional composites of coir/bamboo polypropylene composites was characterized at the macro level, where fibers are mixed at the fiber layer scale. Thin coir and bamboo prepress (a thickness of 1-3 technical fibers) were used for making the hybrid composite samples with the intention of approaching a good mixing at the single fiber level, which is considered hybridization at the micro scale; theoretical studies [11,12] predict a better stress transfer in hybrid composites when the fibers are mixed at the micro level. The correlation between the tensile properties of the fibers and of the hybrid composites was analyzed. In addition, the failure mode and fracture morphology of the hybrid composites were also examined to provide a better understanding of the hybrid effects.

\section{Materials and Methods}

\subsection{Materials}

\subsubsection{Fibers and Polymer Matrix}

Technical coir and bamboo fibers were used in this study. The coir fibers were long coir with fiber length in the range of 200-300 mm, supplied by the Can Tho University of Vietnam, where the fibers were extracted from the husk shell of coconut from the coconut palm (Cocos nucifera L.). The technical bamboo fibers were extracted from bamboo culms of the species Guadua angustifolia (from Colombia), using a novel mechanical extraction process developed by KU Leuven, giving a maximum fiber length between 200 and $350 \mathrm{~mm}$. The extracted coir and bamboo fibers were soaked in hot distilled water at $70{ }^{\circ} \mathrm{C}$ for $2 \mathrm{~h}$, and then smoothly washed with alcohol to remove greases which may attach on the fiber surface during the fiber extraction process, rinsed with deionized water, and dried under vacuum at $90^{\circ} \mathrm{C}$.

Polypropylene (PP) was used as the matrix for composites. The PP was an unmodified grade and supplied in sheet form by Propex GmbH \& Co. KG (Gronau, Germany). The polymer has melt flow rate of $5.2 \mathrm{~g} / 10 \mathrm{~min}$ and melting temperature of $160.6^{\circ} \mathrm{C}$. The mechanical properties of the PP were measured by three point bending test following ASTM 790M, which are presented in Table 1.

\subsubsection{Mechanical Properties}

Tensile properties of the technical fibers were investigated in previous studies [9,10,13-15]. Table 1 shows the tensile strength, E-modulus, and strain at failure of the studied coir and bamboo fibers. The mechanical properties of PP were also assessed and presented.

Table 1. Mechanical properties of studied fibers and polymer matrix.

\begin{tabular}{cccccc}
\hline Material & E-Modulus (GPa) & Strength (MPa) & Strain to Failure (\%) & Density $\left(\mathbf{g} / \mathbf{c m}^{\mathbf{3}}\right)$ & Reference \\
\hline Coir fiber & $4.6-4.9$ & $210-250$ & $18.0-36.7$ & 1.3 & 1.4 \\
Bamboo & $42-50$ & $775-860$ & 1.1 .9 & [10] & [15,16] \\
PP & $1.6-1.8$ & $55-65$ & $>300$ & tested values \\
\hline
\end{tabular}

\subsection{Fabrication of Unidirectional (UD) Hybrid Composites}

\subsubsection{Preparation of UD Coir and Bamboo Prepreg with Polypropylene}

The extracted coir and bamboo fibers were delivered in a bundle and slightly twisted. In order to make UD hybrid composites, it is required that the fibers are properly aligned in one direction. In this work, a procedure for fiber alignment was developed, in which the coir and bamboo fibers were soaked in water, then combed and evenly spread in a thin layer of UD fibers (with thickness of 
1-3 technical fibers). This wet layer was placed between two plastic plates to keep the UD form of the fiber layer, during drying at $70{ }^{\circ} \mathrm{C}$ for three days in an oven. After drying, the UD fiber layers were used for making prepregs with PP matrix.

The prepreg was made by placing a UD fiber layer sandwiched between two layers of thermoplastic films, as seen in (Figure 1). The sandwich was clamped and pressed at approximately $200{ }^{\circ} \mathrm{C}$ by an iron in order to consolidate the fiber and the matrix to form a prepreg.

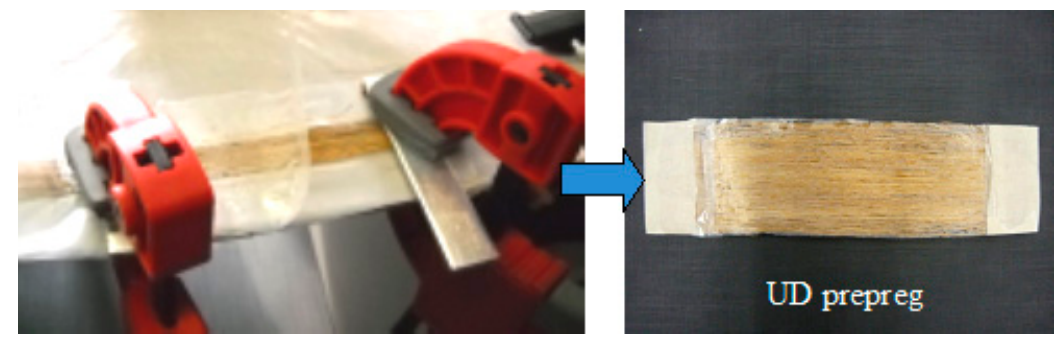

Figure 1. Preparation of UD coir fiber polypropylene prepreg.

\subsubsection{Composite Processing}

UD composites of coir and bamboo fiber with PP matrix were produced using prepregs in order to perform tensile tests. The test samples had dimensions of $15 \mathrm{~mm} \times 250 \mathrm{~mm} \times 2 \mathrm{~mm}$ (width $\times$ length $\times$ thickness) following ASTM 3039 .

For composites processing, the prepregs were cut into the desired dimensions fitting into an Aluminum mold (Figure 2a) with designated stacking sequences. The thickness of the samples was controlled by placing aluminum stoppers at both edges of the mold channels between the upper and lower mold. Six samples of each type could be produced at one time using six channels in the molds. The fiber volume fraction of the composite samples was estimated by the weight of the fibers and the matrix films. Three types of UD composites were produced, including monolithic UD coir/PP, UD bamboo/PP, and UD coir-bamboo/PP composites. The closed mold set-ups were then placed into the Pinette hot press (Figure $2 \mathrm{~b}$ ) for composites fabrication, under processing parameters of $175^{\circ} \mathrm{C}$, at 10 bar pressure and for $15 \mathrm{~min}$, after that the mold was cooled to room temperature under the same pressure.

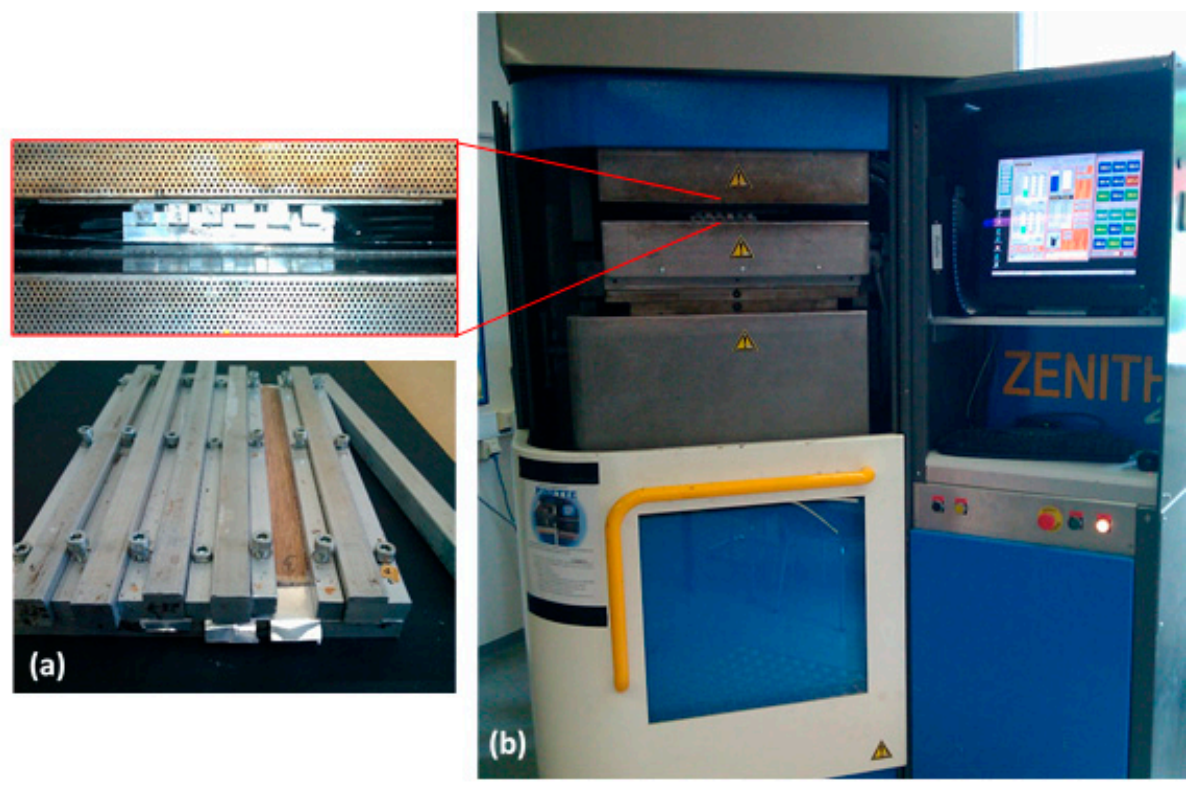

Figure 2. (a) Mold for tensile test samples, and (b) Composite processing in the Pinette hot press. 
The hybrid coir-bamboo/PP composite samples were prepared by stacking coir/PP and bamboo/PP prepregs in a sequence of two layers of coir/PP prepreg at the outside and one layer of bamboo/PP prepreg in the middle. For monolithic composites, six layers of coir/PP and bamboo/PP prepreg were used for producing the composites.

The produced UD coir-bamboo hybrid composites had fiber volume fractions of coir and bamboo fibers of approximately $30 \%$ and $8 \%$, respectively, while the fiber volume fraction of the coir/PP and the bamboo/PP is $44 \%$ and $45 \%$, respectively.

\subsection{Tensile Test and Characterization of Composite Microstructure}

Tensile tests were performed according to the standard ASTM D3039, on composite samples of $15 \mathrm{~mm} \times 200 \mathrm{~mm} \times 2 \mathrm{~mm}$, to which composite end-tabs were glued. A load cell of $5 \mathrm{kN}$ was used and a crosshead speed of $1 \mathrm{~mm} / \mathrm{min}$ was applied. The gauge length between the two clamps was set at $100 \mathrm{~mm}$, while an extensometer with a gauge length of $50 \mathrm{~mm}$ was employed for measuring the sample strain. (Figure 3) shows the set up for the tensile test and some tested samples.

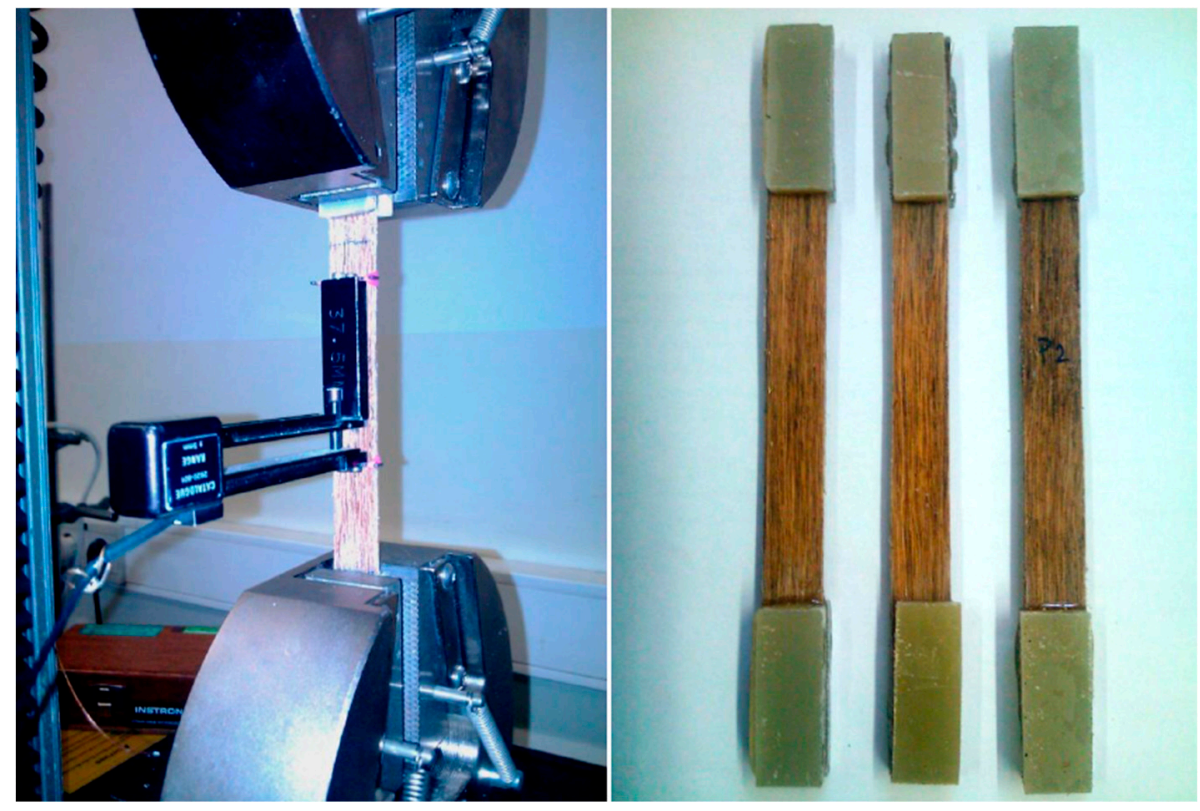

Figure 3. Tensile test (left) and test samples (right).

Various composite systems, including bamboo, coir, and hybrid coir-bamboo in PP, were characterized. Six samples for each type of composite were tested.

Scanning electronic microscopy (SEM) images of the composite cross-sections were taken after failure using a Philips XL 30 FEG scanning electron microscope (FEI Europe B.V., Zaventem, Belgium). The images provide the information of the fracture of the composites including fiber distribution and failure mechanism of the fibers.

\section{Results and Discussion}

\subsection{Tensile Behavior of the Monolithic and Hybrid Composite}

The tensile stress-strain curves of the UD coir-bamboo hybrid composites are presented in Figure 4. It can be seen that the hybrid composites show an almost linear-elastic behavior until a peak stress, and then the stress dramatically decreases to a certain value. From this point on, the stress reduces slowly in a plastic manner. From this behavior, it is suggested that the coir fibers and the bamboo fibers together carry the tensile load until reaching the peak stress, at which point most bamboo fibers (with a low fiber volume fraction of $8 \%$ ) fail, leading to a drop in stress. From this point 
on, the remaining coir fibers continue to bear some stress until the whole composite fails. When comparing the hybrid composites with the mono composites, the bamboo/PP composite fails in a brittle manner at high strength but low strain $(<1 \%)$, and the coir/PP system shows a failure at low strength and somewhat higher strain; the E-modulus and strength of the hybrid composite are situated at intermediate values and there is, furthermore, some residual stress after the peak stress until higher strain values. This demonstrates a hybrid effect when combining strong bamboo fibers with high elongation coir fibers. Moreover, the failure strain of the bamboo fibers in the hybrid composite $(\sim 1.2 \%)$ is higher than in the mono-composite $(\sim 0.8 \%)$, suggesting that the presence of the coir fibers has a beneficial effect on the failure strain of the bamboo fibers. A possible explanation could be the stronger thermal contraction of the coir fibers during cooling after compression molding, leading to a mild compressive residual strain in the bamboo fibers. This effect has also been observed by several studies on hybrid composites [2,16-18].

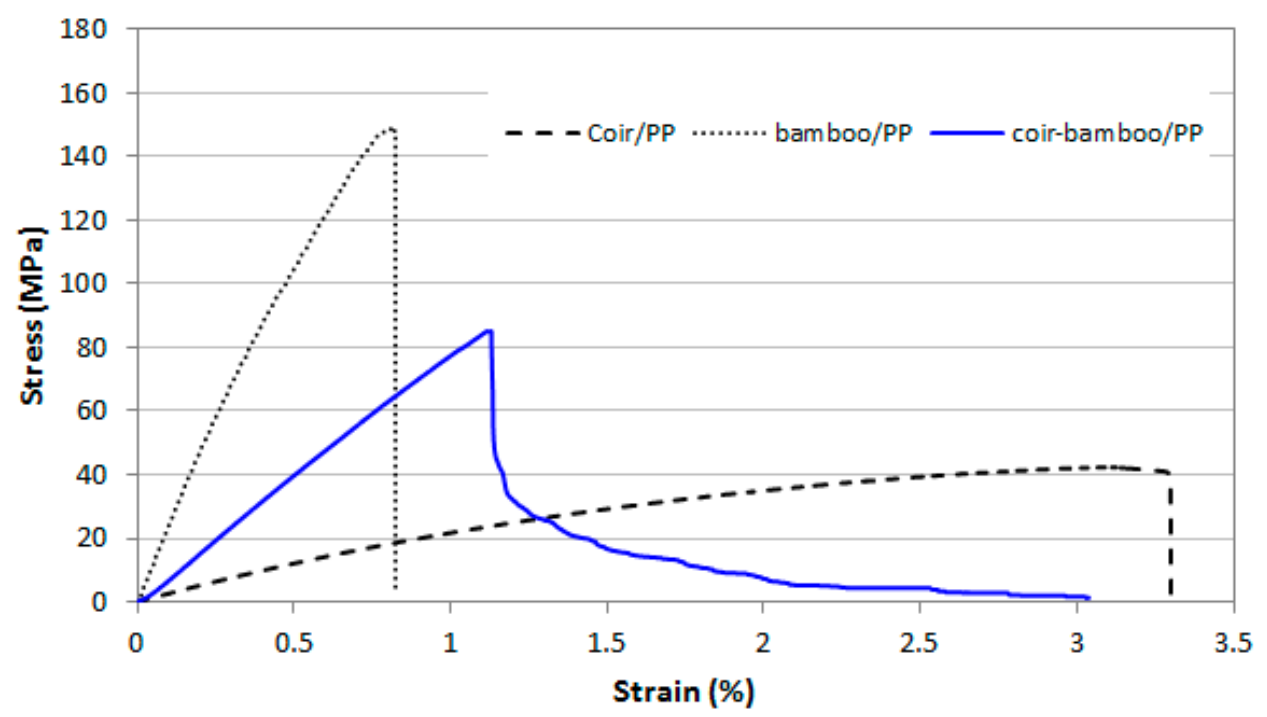

Figure 4. Typical tensile stress-strain curves of UD coir-bamboo/PP hybrid composites displayed together with stress-strain curves of UD mono coir/PP and UD mono bamboo/PP composites.

In (Figure 5b), the cross-section of the hybrid composite shows the distribution of the coir fibers and the bamboo fibers, which are still positioned in three different layers. This means that the hybrid effect in the composite is taking place at the meso level. The composite fracture shows many pulled out coir fibers and the presence of a few broken bamboo fibers. It is likely that the pull-out of the coir fibers delayed the failure of the composite as observed in its stress-strain curve.

The former is confirmed in (Table 2), which once more summarizes the tensile mechanical properties of the hybrid composites. The strain to failure of the hybrid composite is clearly higher than that of the mono bamboo/PP composite. The analysis of the tensile properties is further carried out by comparison with the theoretical values determined by the rule of mixtures.

Table 2. Tensile properties of coir-bamboo/PP hybrid composite, and of mono bamboo/PP and coir/PP composites.

\begin{tabular}{|c|c|c|c|c|c|}
\hline Composites & $V_{\text {coir }}(\%)$ & $V_{\text {bamboo }}(\%)$ & E-Modulus (GPa) & Strength (MPa) & Strain at Failure (\%) \\
\hline Coir-bamboo/PP & 30 & 8 & $7.3 \pm 0.9$ & $87.6 \pm 4.4$ & $2.2 \pm 0.8$ \\
\hline Bamboo/PP & 0 & 45 & $21.7 \pm 2.8$ & $148.3 \pm 10.5$ & $0.9 \pm 0.5$ \\
\hline Coir/PP & 44 & 0 & $2.4 \pm 0.1$ & $43.0 \pm 0.8$ & $3.3 \pm 0.3$ \\
\hline
\end{tabular}


(a)
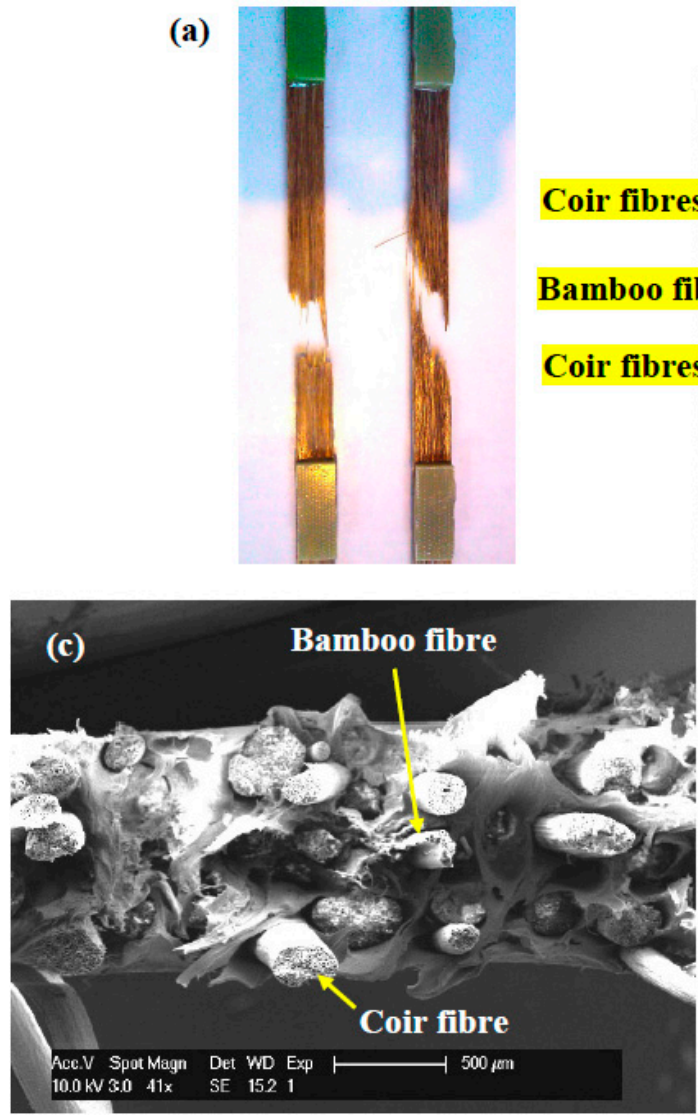

(b)
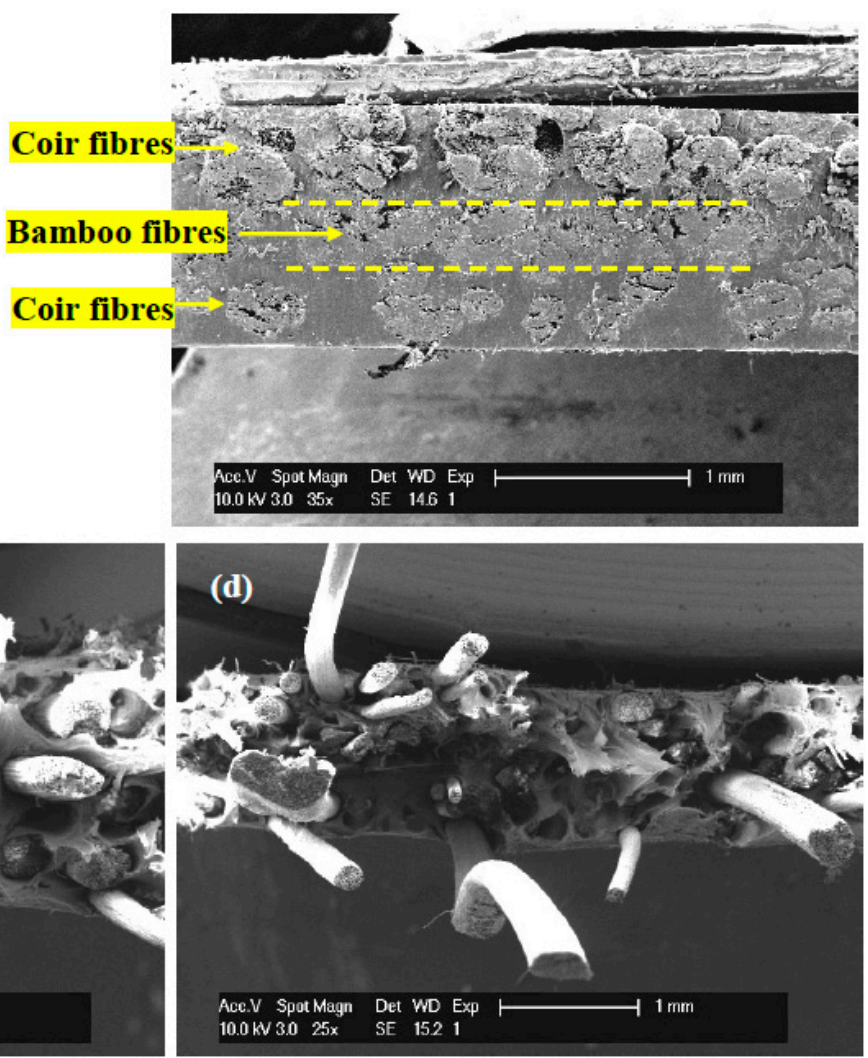

Figure 5. Fracture of the hybrid composite. (a) A typical sample fracture in tensile test; (b) a cross-section of the composite showing coir and bamboo fiber are distributed in three layers; (c) and (d) fracture surface of the composite in the tensile test.

\subsection{Rule of Mixtures for the Hybrid Composite}

\subsubsection{Theoretical E-Modulus and Theoretical Strength of Mono-Composites}

The theoretical E-modulus of coir/PP and bamboo/PP composites, $E_{\text {theo, }}$, is calculated according to the rule of mixtures as shown in Equation (1):

$$
E_{\text {theo }}=V_{f} E_{f}+\left(1-V_{f}\right) E_{m}=V_{f} E_{f}+V_{m} E_{m}
$$

where $V_{f}$ and $V_{m}$ are the volume fractions of fiber and matrix, respectively; $E_{f}$ and $E_{m}$ are the E-modulus of fiber and matrix, respectively.

In the coir and bamboo fiber composites with PP, the fiber failure strain (approximately $36 \%$ for coir and $1.9 \%$ for bamboo fibers) is lower than the matrix failure strain (higher than $300 \%$ ). Thus, the strength of the fibers will determine the failure of the composites; hence the estimation of theoretical strength can be calculated as follows:

$$
\sigma_{\text {theo }}=V_{f} \sigma_{f}^{*}+V_{m} \sigma_{m}^{\prime}
$$

where $\sigma_{f}^{*}$ is the fiber strength, and $\sigma_{m}^{\prime}$ is the matrix stress at fiber failure strength. 
3.2.2. Theoretical E-modulus and Theoretical Strength of Hybrid Composite

The theoretical E-modulus of the hybrid composite is calculated as:

$$
E_{\text {theo }}=E_{\text {coir }} V_{\text {coir }}+E_{\text {bamboo }} V_{\text {bamboo }}+E_{P P} V_{P P}
$$

As illustrated by Figure 6, the theoretical strength is estimated as follows:

(i) If $V_{\text {bamboo }}$ is very low compared to $V_{\text {coir }}$ : the strength of the composite is determined by coir fiber strength. In this case, the coir fibers can carry load after the failure of the bamboo fibers, then

$$
\sigma_{\text {theo }}=\sigma_{\text {coir }}^{*} V_{\text {coir }}+\sigma_{P P}^{\prime} V_{P P}
$$

(ii) If $V_{\text {bamboo }}$ is high. Then, the composite strength is dependent on bamboo fiber strength:

$$
\sigma_{\text {theo }}=\sigma_{\text {coir }}^{\prime} V_{\text {coir }}+\sigma_{\text {bamboo }}^{*} V_{\text {bamboo }}+\sigma_{P P}^{\prime} V_{P P}
$$

where $\sigma_{\text {coir }}^{\prime}$ and $\sigma_{P P}^{\prime}$ are the stress in the coir fiber and the stress in the PP, respectively, at the failure strain of the bamboo fiber (Figure 6).

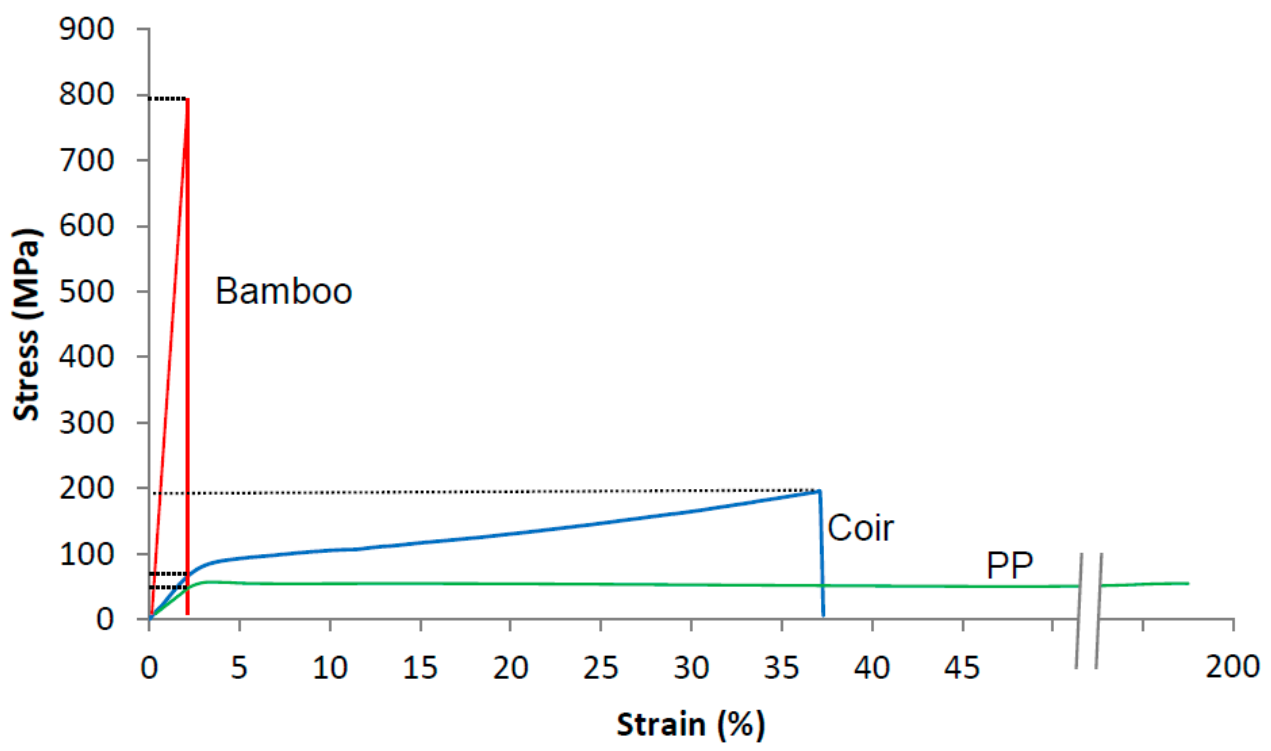

Figure 6. Mono-material properties used as input to calculate the properties following the rule of mixtures of the coir-bamboo/PP hybrid composite.

With the fiber volume fraction of coir fibers and of bamboo fibers at $30 \%$ and $8 \%$, respectively, the theoretical strength of the composite calculated following Equation (4) is $111 \mathrm{MPa}$, which is lower than the value calculated following Equation (5) (120.8 MPa). The result shows the bamboo fiber load is high enough to determine the hybrid composite strength. Hence, the theoretical strength of the composite will be calculated according to Equation (5).

The theoretical E-modulus and strength of the hybrid composite is calculated following Equations (3) and (5) and shown in (Table 3). The efficiency factors (the experimental values normalized to the theoretical values) are also estimated. It can be seen that the strength efficiency factor is surprisingly high (0.73) compared to the values of the mono coir/PP (0.32) and bamboo/PP (0.38) systems. As discussed above, there likely exists a beneficial effect of the residual strain in bamboo fibers, leading to an important increase in failure stress and, hence, a higher contribution to the overall strength of the hybrid composite. Meanwhile, the premature failure of coir/PP and bamboo/PP 
(reflected with the relatively low strength efficiency factors) could be caused by low interfacial adhesion between the fibers and PP matrix.

Table 3. Theoretical E-modulus and strength of the hybrid composite estimated by the rule of mixtures, and the efficiency factors of E-modulus and strength.

\begin{tabular}{ccccc}
\hline Composite & Theoretical E-Modulus (GPa) & Efficiency Factor of E-Modulus & Theoretical Strength (MPa) & Efficiency Factor of Strength \\
\hline Coir-bamboo/PP & 6.1 & 1.22 & $120.8^{1}$ & 0.73 \\
\hline Coir/PP & 3.2 & 0.76 & 134.8 & 0.32 \\
\hline Bamboo/PP & 23.5 & 0.92 & 393 & 0.38 \\
\hline & 1 the theoretical strength of the composite is calculated according to Equation (5).
\end{tabular}

\section{Conclusions}

The tensile behavior of coir-bamboo fiber hybrid composites in PP was investigated, where the coir fiber and bamboo fiber were mixed at the meso level by layer-by-layer stacking of UD fiber prepregs. With a low bamboo fiber fraction, a hybrid effect with an increase of composite strain to failure was obtained, which can be attributed to the high strain to failure of the coir fibers; the bamboo fibers provided high stiffness and strength to the composites. The results show that a positive hybrid effect is obtained when a low bamboo fiber fraction is hybridized with a higher fraction of coir fibers. Different fiber mixing levels and variation of fiber loading can be considered to explore more synergetic properties for applications of the hybrid composites.

Author Contributions: Conceptualization: L.Q.N.T. and A.W.V.V.; methodology: L.Q.N.T. and A.W.V.V.; investigation: L.Q.N.T. and C.F.; writing: L.Q.N.T.; supervision: I.V.

Funding: This research received no external funding.

Conflicts of Interest: The authors declare no conflict of interest.

\section{References}

1. Swolfs, Y.; Verpoest, I.; Gorbatikh, L. Recent advances in fibre-hybrid composites: Materials selection, opportunities and applications. Int. Mater. Rev. 2019, 64, 181-215. [CrossRef]

2. Manders, P.W.; Bader, M. The strength of hybrid glass/carbon fibre composites. J. Mater. Sci. 1981, 16, 2246-2256. [CrossRef]

3. Zhang, J.; Chaisombat, K.; He, S.; Wang, C.H. Hybrid composite laminates reinforced with glass/carbon woven fabrics for lightweight load bearing structures. Mater. Des. 2012, 36, 75-80. [CrossRef]

4. Wisnom, M.R.; Czél, G.; Swolfs, Y.; Jalalvand, M.; Gorbatikh, L.; Verpoest, I. Hybrid effects in thin ply carbon/glass unidirectional laminates: Accurate experimental determination and prediction. Compos. Part $A$ Appl. Sci. Manuf. 2016, 88, 131-139. [CrossRef]

5. Zhang, Y.; Li, Y.; Ma, H.; Yu, T. Tensile and interfacial properties of unidirectional flax/glass fiber reinforced hybrid composites. Compos. Sci. Technol. 2013, 88, 172-177. [CrossRef]

6. Swolfs, Y.; Crauwels, L.; Van Breda, E.; Gorbatikh, L.; Hine, P.; Ward, I.; Verpoest, I. Tensile behaviour of intralayer hybrid composites of carbon fibre and self-reinforced polypropylene. Compos. Part A Appl. Sci. Manuf. 2014, 59, 78-84. [CrossRef]

7. Pegoretti, A.; Fabbri, E.; Migliaresi, C.; Pilati, F. Intraply and interply hybrid composites based on E-glass and poly (vinyl alcohol) woven fabrics: Tensile and impact properties. Polym. Int. 2004, 53, 1290-1297. [CrossRef]

8. Hine, P.; Bonner, M.; Ward, I.M.; Swolfs, Y.; Verpoest, I.; Mierzwa, A. Hybrid carbon fibre/nylon 12 single polymer composites. Compos. Part A Appl. Sci. Manuf. 2014, 65, 19-26. [CrossRef]

9. Defoirdt, N.; Biswas, S.; De Vriese, L.; Van Acker, J.; Ahsan, Q.; Gorbatikh, L.; Van Vuure, A.; Verpoesta, L.; Trana, L.Q.N. Assessment of the tensile properties of coir, bamboo and jute fibre. Compos. Part A Appl. Sci. Manuf. 2010, 41, 588-595. [CrossRef]

10. Tran, L.Q.N.; Minh, T.N.; Fuentes, C.A.; Chi, T.T.; Van Vuure, A.W.; Verpoest, I. Investigation of microstructure and tensile properties of porous natural coir fibre for use in composite materials. Indust. Crop. Prod. 2015, 65, 437-445. [CrossRef] 
11. Taketa, I.; Ustarroz, J.; Gorbatikh, L.; Lomov, S.V.; Verpoest, I. Interply hybrid composites with carbon fiber reinforced polypropylene and self-reinforced polypropylene. Compos. Part A Appl. Sci. Manuf. 2010, 41, 927-932. [CrossRef]

12. Taketa, I. Analysis of Failure Mechanisms and Hybrid Effects in Carbon Fibre Reinforced Thermoplastic Composites. Ph D. Thesis, Katholieke Universiteit Leuven, Leuven, Belgium, 2011.

13. Osorio, L.; Trujillo, E.; Van Vuure, A.W.; Verpoest, I. Morphological aspects and mechanical properties of single bamboo fibers and flexural characterization of bamboo/epoxy composites. J. Reinf. Plast. Compos. 2011, 30, 396-408. [CrossRef]

14. Osorio, L.; Trujillo, E.; Lens, F.; Ivens, J.; Verpoest, I.; Van Vuure, A.W. In-depth study of the microstructure of bamboo fibres and their relation to the mechanical properties. J. Reinf. Plast. Compos. 2018, 37, 1099-1113. [CrossRef]

15. Trujillo, E.; Moesen, M.; Osorio, L.; Van Vuure, A.W.; Ivens, J.; Verpoest, I. Bamboo fibres for reinforcement in composite materials: Strength Weibull analysis. Compos. Part A Appl. Sci. Manuf. 2014, 61, 115-125. [CrossRef]

16. Zweben, C. Tensile strength of hybrid composites. J. Mater. Sci. 1977, 12, 1325-1337. [CrossRef]

17. Bader, M.; Manders, P. The strength of hybrid glass/carbon fibre composites, part 1: Failure strain enhancement and failure mode. J. Mater. Sci. 1981, 16, 2233-2245.

18. Pitkethly, M.; Bader, M. Failure modes of hybrid composites consisting of carbon fibre bundles dispersed in a glass fibre epoxy resin matrix. J. Phys. D Appl. Phys. 1987, 20, 315. [CrossRef]

(C) 2019 by the authors. Licensee MDPI, Basel, Switzerland. This article is an open access article distributed under the terms and conditions of the Creative Commons Attribution (CC BY) license (http://creativecommons.org/licenses/by/4.0/). 